\title{
The developmental origins of sarcopenia
}

\author{
Avan Aihie Sayer, Holly Syddall, Helen Martin, Harnish Patel, Daniel Baylis, and Cyrus \\ Cooper \\ MRC Epidemiology Resource Centre, University of Southampton, Southampton, UK
}

\section{Introduction}

Sarcopenia is defined as the loss of skeletal muscle mass and strength with age1. There is increasing recognition of the serious health consequences of sarcopenia both in terms of disability2, morbidity3 and mortality4, and in terms of significant healthcare costs5. Adult determinants of sarcopenia including age, gender, size, levels of physical activity and heritability have been well described1;6-8. In particular the place of physical activity and resistance exercise training as the most effective intervention to slow loss is widely accepted $9 ; 10$.

Nevertheless there remains considerable unexplained variation in muscle mass and strength between older individuals which may be partly explained by the observation that muscle mass and strength in later life reflect not only the rate of loss but also the peak attained earlier in life (Figure 1). To date most observational and interventional epidemiological studies have focused on factors modifying decline in later life but this life course model of sarcopenia additionally focuses attention on the determinants of peak muscle mass and strength attained in early adulthood.

\section{Developmental origins of health and disease}

Epidemiological research into the developmental origins of health and disease has shown that early environmental influences on growth and development may have long-term consequences for human health 11 . This phenomenon is called programming, a process whereby a stimulus or insult acting at a critical period of development has lasting or lifelong significance12. Clues to the mechanisms have come from evolutionary biology. Darwin described how animal populations have two adaptation strategies: natural selection based on genetic variation acting over many generations and developmental plasticity acting within the lifetime of an individual.

Developmental plasticity is defined as 'the ability of a single genotype to produce more than one alternative form of structure, physiological state or behaviour in response to environmental conditions'. This enables production of a range of phenotypes that are better suited to their environment than would be possible if the same phenotype were produced regardless of environmental condition13s. These early adaptations in phenotype may not only be in response to the prevailing conditions but involve preparation for the "predicted" postnatal environment. This has been called the predictive adaptive response. When the prediction is correct, the phenotype functions well, however when a mismatch occurs between the predicted and the actual environment, the chosen phenotype may be associated with an increased disease risk over the longer term 14.

Address for correspondence: Avan Aihie Sayer, MRC Epidemiology Resource Centre, University of Southampton, Southampton General Hospital, Southampton, SO16 6YD, Email: aas@mrc.soton.ac.uk. 
It is likely that the induction of persistent changes to tissue structure and function by differences in the early life environment involves life-long alterations to the regulation of gene transcription and the mechanisms are being explored15. There is evidence for changes in the epigenetic regulation of transcription, specifically DNA methylation and covalent modification of histones, in the induction of an altered phenotype by nutritional constraint in early life. For example one study showed that feeding a protein restriction diet to rats during pregnancy induced hypomethylation of the peroxisome proliferation-activated receptor alpha (PPARa) and glucocorticoid receptor (GR) gene promoters and increased expression of PPARa and GR in the liver of the offspring16. More recent work has shown that these effects persist into adulthood 17.

\section{Developmental plasticity of muscle: animal models}

There is good evidence from animal models for developmental plasticity of muscle. A recent study showed that peri-implantation and late gestation maternal undernutrition differentially affected fetal sheep skeletal muscle development 18 . There was evidence of reduced slowtwitch myofibre and capillary density in the fetal triceps but not the soleus with both forms of undernutrition. This reduction in fibre density was associated with higher insulin receptor, glucose transporter GLUT-4 and type 1 insulin growth factor receptor mRNA levels. It was postulated that these findings were consistent with a redistribution of resources at the expense of specific peripheral tissues by early and late gestation undernutrition which may be mediated by a decrease in capillary density.

Other studies involving experimental manipulation of early nutrition have shown that prenatal maternal diet restriction is associated with reduced neonatal muscle weight in sheep19, and a reduction in postnatal muscle fibre number in the pig20, guinea pig21, and rat22. There is also evidence that these effects persist $23 ; 24$. This contrasts with the beneficial effects on ageing of dietary restriction instituted later in life 25 .

Muscle fibre number is a critical determinant of muscle mass and strength and a number of studies have described the regulators of myofibre number, type and size26. Genetic factors appear to be the major influence on primary fibre number whereas environmental factors such as maternal undernutrition have a predominant effect on the growth and development of secondary fibres 27 . However the concept that there is a fixed number of muscle fibres determined by birth, with subsequent growth only achieved by increase in fibre size, is probably now outdated. Recent evidence suggests that post-mitotic myonuclei lying within mature myofibres might be able to reform myoblasts or stem cells, and there is increasing recognition of the role that satellite cells play in postnatal muscle growth and regeneration $28 ; 29$.

\section{Developmental influences on human muscle: epidemiological evidence}

Evidence for developmental influences on human muscle has come from a series of observational epidemiological studies linking small size at birth, as a marker of adverse early environmental conditions, with reduced adult muscle mass and strength.

\section{Studies of muscle strength}

The association between low birth weight and reduced muscle strength was first reported in the Hertfordshire Ageing Study, a birth cohort study of men and women born in Hertfordshire UK between 1920 and 1930 and still living there 60 - 70 years later30. They had historical health visitor records of weight at birth and one year and were traced through the National Health Service Central Registry in Southport UK. Following a home interview, 717 people attended a local clinic for measurement of current size and markers of ageing in 
different body systems including grip strength. Lower birth weight and weight at one year were significantly associated with lower grip strength in later life. These relationships remained significant although attenuated after allowing for adult size suggesting that an adverse early environment may have an effect on muscle quality as well as quantity.

The association between birth weight and adult grip strength has been replicated in a younger Hertfordshire cohort born 1931-193931 (Figure 2) and in a national birth cohort of middle-aged men and women born in 1946 and participating in the National Survey of Health and Development32. More recent work has demonstrated a similar effect size of birth weight on adult muscle strength in young women aged 20 -34 years taking part in the Southampton Women's Survey suggesting an association between early size and peak muscle strength rather than decline33. To date, the relationship between birth weight and grip strength been replicated in ten studies summarised in Table 1.

It has been possible to add to these findings with a more detailed life course approach using longitudinal data collected in the National Survey of Health and Development34. Grip strength and body size were measured in a representative British sample of 1406 men and 1444 women who were 53 years old and had prospective childhood data on weight, height, motor milestones, cognitive ability and information on lifetime social class, current physical activity and health status. Birth weight and pre-pubertal height gain were associated with midlife grip strength, independently of later weight and height gain. Pubertal growth was also independently associated with midlife grip strength; for men weight gain during puberty was beneficial, whereas for women it was height gain. Those participants with earlier infant motor development had better midlife grip strength, which was partly confounded by the growth trajectory. This suggests that components of prenatal, prepubertal, and pubertal growth have long-term effects on midlife grip strength35.

\section{Studies of muscle mass}

Studies investigating the relationship between growth in early life and muscle mass have demonstrated consistent findings linking low birth weight with reduced muscle mass. A study of older men participating in the Hertfordshire Cohort Study showed that birth weight was significantly positively associated with fat-free mass but not with measures of adult fat mass. In contrast, weight at one year was associated with fat-free mass and adult fat mass estimated using anthropometry 36.

Similar findings were observed in studies of men and women using urinary creatinine excretion 37 and dual x-ray absorptiometry 38 to estimate muscle mass. More recently a study on the Helsinki birth cohort Finland has replicated the relationships between small size at birth, lower muscle mass and reduced grip strength in older people39. Studies of birth weight and muscle mass in earlier stages of life demonstrate similar findings for children40, teenagers 41 and young adults 42 .

\section{Effect size}

\section{Absolute effect size}

We reviewed the published evidence for an association between lower birth weight and reduced grip strength in later life and derived a pooled estimate for the effect of birth weight on grip strength in absolute terms.

Methods used for the review—Relevant independent articles were identified by searching Pubmed, OVID Medline and ISI Web of Knowledge (search terms: birth weight and grip strength, hand grip or hand strength). Data abstraction forms were used to record the location, gender composition, study size, age range, measurement protocols, and the 
unadjusted relationship between birth weight and grip strength in each study; this information was collated in tabular form. For studies where a regression coefficient for the relationship between birth weight and grip strength was available, Stata 10 was used to: produce a forest plot; test for homogeneity using the $\mathrm{Q}$ statistic; estimate the inverse variance weighted fixed effects pooled coefficient for the relationship between birth weight and grip strength; and to assess the influence of individual studies 43 .

Results of the review-Ten independent articles described the relationship between birth weight and grip strength in later life (Table 1). Four of these studied small groups of low birth weight versus normal birth weight individuals and only followed participants to childhood or early adulthood (5, 15, 17 or 23 years of age); all demonstrated lower grip strength amongst lower birth weight individuals. The remaining six studies considered the full range of birth weight among men and women, ranged in size from 316 to 1,562 participants, with follow-up ages ranging from 16 to 73 years of age. Comparable measurement protocols ascertained peak grip strength in each study.

A forest plot (Figure 3) showed remarkable homogeneity of association between birth weight and grip strength (Q-statistic 7.36 on 9df with sub-studies for men and women entered separately in the analysis, $\mathrm{p}=0.60$ ) with a pooled estimate of a $2.06 \mathrm{~kg}$ increase in grip strength per kilogram increase in birth weight $(95 \%$ CI 1.77, 2.35). Effect sizes were homogenous for men and women $(\mathrm{p}=0.17)$ and no individual study unduly influenced the pooled estimate. The studies considered different potential confounders so no pooled adjusted estimate of effect size could be obtained; adult size typically attenuated, but did not remove, the birth weight versus grip strength relationship.

\section{Relative effect size}

The data from epidemiological studies also allow consideration of the effect of birth weight on grip strength relative to the effect of the other major determinants of strength such as age. For example grip strength increased by $2.42 \mathrm{~kg}$ per kilogram of birth weight in men aged 59 - 71 years taking part in the Hertfordshire Cohort Study (HCS). This association accounted for $2.2 \%$ of the variance in adult grip strength which is comparable to the $3.6 \%$ of variance in grip strength explained by age. It is likely that birth weight also contributes to the $16.2 \%$ of variance in grip strength accounted for by adult height as there is evidence for tracking of size throughout life 32 .

\section{Underlying mechanisms}

There is considerable interest in which aspects of the early environment underlie these epidemiological associations. Few retrospective cohort studies have sufficiently detailed data on prenatal and postnatal environmental influences to assess specific effects on long term muscle mass and strength but these questions are being addressed in the prospective Southampton Women's Survey44. This study has recruited over 12,500 women living in the city of Southampton and interviewed them to assess health, body composition, lifestyle and diet. They have been followed in subsequent pregnancies and their offspring followed through childhood with the aim of identifying prospectively the influence of the preconceptional and antenatal environment on the growth and development of the fetus, infant and child.

Using data from 448 mother-offspring pairs in this cohort it has been possible to examine parental influences on neonatal body composition ascertained by dual x-ray absorptiometry45. Taller women and those with higher parity had offspring with increased birth weight, fat and lean mass whereas women who smoked during pregnancy had smaller babies, with reduced fat and lean mass. Maternal walking speed was negatively associated 
with birth weight and fat mass positively predicted neonatal total and proportionate fat but was negatively correlated with proportionate lean mass. Future analyses will focus on the influence of maternal diet on neonatal body composition and childhood grip strength.

\section{Next stage}

There has been little work linking early environmental influences with changes in human muscle at a molecular or cellular level. One small study involving 27 adult women looked at the relationship between size at birth and skeletal muscle morphology but did not find significant associations 46 . In contrast, a more recent study focused on a group of 20 young men and showed altered skeletal muscle fibre composition and size in those with low birth weight 47 . This work needs to be taken forward with studies of older people designed to elucidate the underlying molecular and cellular mechanisms of developmental influences on sarcopenia48.

\section{References}

1. Morley JE, Baumgartner RN, Roubenoff R, Mayer J, Nair KS. Sarcopenia. J Lab Clin Med. 2001; 137:231-43. [PubMed: 11283518]

2. Sayer AA, Syddall HE, Martin HJ, Dennison EM, Roberts HC, Cooper C. Is grip strength associated with health-related quality of life? Findings from the Hertfordshire Cohort Study. Age Ageing. 2006; 35:409-15. [PubMed: 16690636]

3. Sayer AA, Dennison EM, Syddall HE, Gilbody HJ, Phillips DI, Cooper C. Type 2 diabetes, muscle strength, and impaired physical function: the tip of the iceberg? Diabetes Care. 2005; 28:2541-2. [PubMed: 16186295]

4. Gale CR, Martyn CN, Cooper C, Sayer AA. Grip strength, body composition, and mortality. Int J Epidemiol. 2007; 36:228-35. [PubMed: 17056604]

5. Janssen I, Shepard DS, Katzmarzyk PT, Roubenoff R. The healthcare costs of sarcopenia in the United States. J Am Geriatr.Soc. 2004; 52:80-5. [PubMed: 14687319]

6. Marcell TJ. Sarcopenia: causes, consequences, and preventions. J.Gerontol.A Biol.Sci.Med.Sci. 2003; 58:M911-M916. [PubMed: 14570858]

7. Roubenoff R. Sarcopenia and its implications for the elderly. Eur J Clin Nutr. 2000; 54:S40-S47. [PubMed: 11041074]

8. Arden NK, Spector TD. Genetic influences on muscle strength, lean body mass, and bone mineral density: a twin study. J Bone Miner Res. 1997; 12:2076-81. [PubMed: 9421240]

9. Vincent KR, Braith RW, Feldman RA, Magyari PM, Cutler RB, Persin SA, et al. Resistance exercise and physical performance in adults aged 60 to 83. J Am Geriatr.Soc. 2002; 50:1100-7. [PubMed: 12110072]

10. Skelton DA, Young A, Greig CA, Malbut KE. Effects of resistance training on strength, power, and selected functional abilities of women aged 75 and older. J Am Geriatr.Soc. 1995; 43:1081-7. [PubMed: 7560695]

11. Bateson P, Barker D, Clutton-Brock T, Deb D, D’Udine B, Foley RA, et al. Developmental plasticity and human health. Nature. 2004; 430:419-21. [PubMed: 15269759]

12. Lucas, A. Programming by early nutrition in man. In: Bock, GR.; Whelan, J., editors. The childhood environment and adult disease; Ciba Foundation Symposium 156; Chichester: John Wiley. 1991; p. 38-50.

13. West-Eberhard MJ. Phenotypic plasticity and the origins of diversity. Ann Rev Ecol Syst. 1989; 20:249-78.

14. Gluckman PD, Hanson MA. Living with the past: evolution, development, and patterns of disease. Science. 2004; 305:1733-6. [PubMed: 15375258]

15. Burdge GC, Hanson MA, Slater-Jefferies JL, Lillycrop KA. Epigenetic regulation of transcription: a mechanism for inducing variations in phenotype (fetal programming) by differences in nutrition during early life? Br.J Nutr. 2007:1-11. 
16. Lillycrop KA, Phillips ES, Jackson AA, Hanson MA, Burdge GC. Dietary protein restriction of pregnant rats induces and folic acid supplementation prevents epigenetic modification of hepatic gene expression in the offspring. J Nutr. 2005; 135:1382-6. [PubMed: 15930441]

17. Lillycrop KA, Phillips ES, Torrens C, Hanson MA, Jackson AA, Burdge GC. Feeding pregnant rats a protein-restricted diet persistently alters the methylation of specific cytosines in the hepatic PPARalpha promoter of the offspring. Br.J Nutr. 2008:1-5.

18. Costello PM, Rowlerson A, Astaman NA, Anthony F, Aihie Sayer A, Cooper C, et al. Periimplanatation and late gestation maternal undernutrition differentially affect fetal sheep skeletal muscle development. J Physiol. 2008 In press.

19. Greenwood PL, Hunt AS, Hermanson JW, Bell AW. Effects of birth weight and postnatal nutrition on neonatal sheep: II. Skeletal muscle growth and development. J Anim Sci. 2000; 78:50-61. [PubMed: 10682802]

20. Dwyer CM, Stickland NC, Fletcher JM. The influence of maternal nutrition on muscle fiber number development in the porcine fetus and on subsequent postnatal growth. J Anim Sci. 1994; 72:911-7. [PubMed: 8014156]

21. Dwyer CM, Madgwick AJ, Ward SS, Stickland NC. Effect of maternal undernutrition in early gestation on the development of fetal myofibres in the guinea-pig. Reprod Fertil Dev. 1995; 7:1285-92. [PubMed: 8848601]

22. Wilson SJ, Ross JJ, Harris AJ. A critical period for formation of secondary myotubes defined by prenatal undernourishment in rats. Development. 1988; 102:815-21. [PubMed: 3168790]

23. Prakash YS, Fournier M, Sieck GC. Effects of prenatal undernutrition on developing rat diaphragm. J Appl.Physiol. 1993; 75:1044-52. [PubMed: 8226510]

24. Pond WG, Yen JT, Mersmann HJ, Maurer RR. Reduced mature size in progeny of swine severely restricted in protein intake during pregnancy. Growth Dev.Aging. 1990; 54:77-84. [PubMed: 1705922]

25. Aihie Sayer, A.; Cooper, C. Early undernutrition: good or bad for longevity?. In: Watson, RR., editor. Handbook of nutrition in the aged. Boca Raton: CRC Press Inc; 2000. p. 97-106.

26. Dauncey MJ, Gilmour RS. Regulatory factors in the control of muscle development. Proc Nutr Soc. 1996; 55:543-59. [PubMed: 8832818]

27. Maltin CA, Delday MI, Sinclair KD, Steven J, Sneddon AA. Impact of manipulations of myogenesis in utero on the performance of adult skeletal muscle. Reproduction. 2001; 122:35974. [PubMed: 11597302]

28. Bailey P, Holowacz T, Lassar AB. The origin of skeletal muscle stem cells in the embryo and the adult. Curr Opin Cell Biol. 2001; 13:679-89. [PubMed: 11698183]

29. Stewart CE. The physiology of stem cells: potential for the elderly patient. J Musculoskelet.Neuronal.Interact. 2004; 4:179-83. [PubMed: 15615121]

30. Sayer AA, Cooper C, Evans JR, Rauf A, Wormald RP, Osmond C, et al. Are rates of ageing determined in utero? Age Ageing. 1998; 27:579-83. [PubMed: 12675097]

31. Sayer AA, Syddall HE, Gilbody HJ, Dennison EM, Cooper C. Does sarcopenia originate in early life? Findings from the Hertfordshire Cohort Study. J Gerontol. 2004; 59A:930-4.

32. Kuh D, Bassey J, Hardy R, Aihie Sayer A, Wadsworth M, Cooper C. Birth weight, childhood size, and muscle strength in adult life: evidence from a birth cohort study. Am J Epidemiol. 2002; 156:627-33. [PubMed: 12244031]

33. Inskip HM, Godfrey KM, Martin HJ, Simmonds SJ, Cooper C, Aihie Sayer A. Size at birth and its relation to muscle strength in young adult women. J Int Med. 2007 In press.

34. Wadsworth M, Kuh D, Richards M, Hardy R. Cohort Profile: The 1946 National Birth Cohort (MRC National Survey of Health and Development). Int.J Epidemiol. 2006; 35:49-54. [PubMed: 16204333]

35. Kuh D, Hardy R, Butterworth S, Okell L, Wadsworth M, Cooper C, et al. Developmental origins of midlife grip strength: findings from a birth cohort study. J Gerontol.A Biol.Sci.Med Sci. 2006; 61:702-6. [PubMed: 16870632]

36. Sayer AA, Syddall HE, Dennison EM, Gilbody HJ, Duggleby SL, Cooper C, et al. Birth weight, weight at one year and body composition in older men: findings from the Hertfordshire Cohort Study. Am J Clin Nutr. 2004; 80:199-203. [PubMed: 15213049] 
37. Phillips DIW. Relation of fetal growth to adult muscle mass and glucose tolerance. Diab Med. 1995; 12:686-90.

38. Gale CR, Martyn CN, Kellingray S, Eastell R, Cooper C. Intrauterine programming of adult body composition. J Clin Endocrinol Metab. 2001; 86:267-72. [PubMed: 11232011]

39. Yliharsila H, Kajantie E, Osmond C, Forsen T, Barker DJ, Eriksson JG. Birth size, adult body composition and muscle strength in later life. Int J Obes.(Lond). 2007 In press.

40. Hediger ML, Overpeck MD, Kuczmarski RJ, McGlynn A, Maurer KR, Davis WW. Muscularity and fatness of infants and young children born small-or large-for-gestational-age. Pediatrics. 1998; 102:E60. [PubMed: 9794990]

41. Singhal A, Wells J, Cole TJ, Fewtrell M, Lucas A. Programming of lean body mass: a link between birth weight, obesity, and cardiovascular disease? Am J Clin Nutr. 2003; 77:726-30. [PubMed: 12600868]

42. Kahn HS, Narayan KM, Williamson DF, Valdez R. Relation of birth weight to lean and fat thigh tissue in young men. Int J Obes Relat Metab Disord. 2000; 24:667-72. [PubMed: 10878671]

43. BMJ Books. 2001. Systematic reviews in health care.

44. Inskip HM, Godfrey KM, Robinson SM, Law CM, Barker DJ, Cooper C. Cohort profile: The Southampton Women's Survey. Int.J Epidemiol. 2005

45. Harvey NC, Poole JR, Javaid MK, Dennison EM, Robinson S, Inskip HM, et al. Parental determinants of neonatal body composition. J Clin Endocrinol Meta b. 2007; 92:523-6.

46. Thompson CH, Sanderson AL, Sandeman D, Stein C, Borthwick A, Radda GK, et al. Fetal growth and insulin resistance in adult life: role of skeletal muscle morphology. Clin Sci (Colch). 1997; 92:291-6. [PubMed: 9093010]

47. Jensen CB, Storgaard H, Madsbad S, Richter EA, Vaag AA. Altered skeletal muscle fiber composition and size precede whole-body insulin resistance in young men with low birth weight. J Clin Endocrinol Metab. 2007; 92:1530-4. [PubMed: 17284623]

48. Aihie Sayer A, Cooper C. Aging, sarcopenia and the life course. Rev Clin Gerontol. 2007; 16:265274.

49. Singh GR, Sayers SM. Birth weight, current body composition and grip strength in an aboriginal birth cohort. Early Hum Dev. 2006:S156.

50. Saigal S, Stoskopf B, Boyle M, Paneth N, Pinelli J, Streiner D, et al. Comparison of current health, functional limitations, and health care use of young adults who were born with extremely low birth weight and normal birth weight. Pediatrics. 2007; 119:e562-e573. [PubMed: 17332176]

51. Rogers M, Fay TB, Whitfield MF, Tomlinson J, Grunau RE. Aerobic capacity, strength, flexibility, and activity level in unimpaired extremely low birth weight (<or=800 g) survivors at 17 years of age compared with term-born control subjects. Pediatrics. 2005; 116:e58-e65. [PubMed: 15997047]

52. Martorell R, Ramakrishnan U, Schroeder DG, Melgar P, Neufeld L. Intrauterine growth retardation, body size, body composition and physical performance in adolescence. Eur.J Clin Nutr. 1998; 52(Suppl 1):S43-S52. [PubMed: 9511019]

53. Ford GW, Kitchen WH, Doyle LW. Muscular strength at 5 years of children with a birthweight under 1500 g. Aust.Paediatr.J. 1988; 24:295-6. [PubMed: 3228397] 


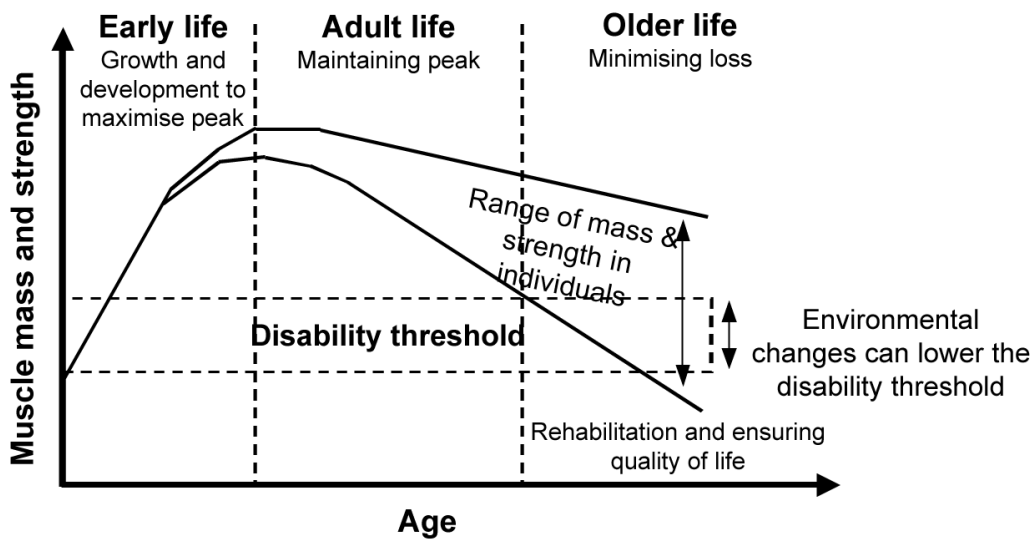

Modified WHO/HPS, Geneva 2000

Figure 1.

A life course model of sarcopenia 


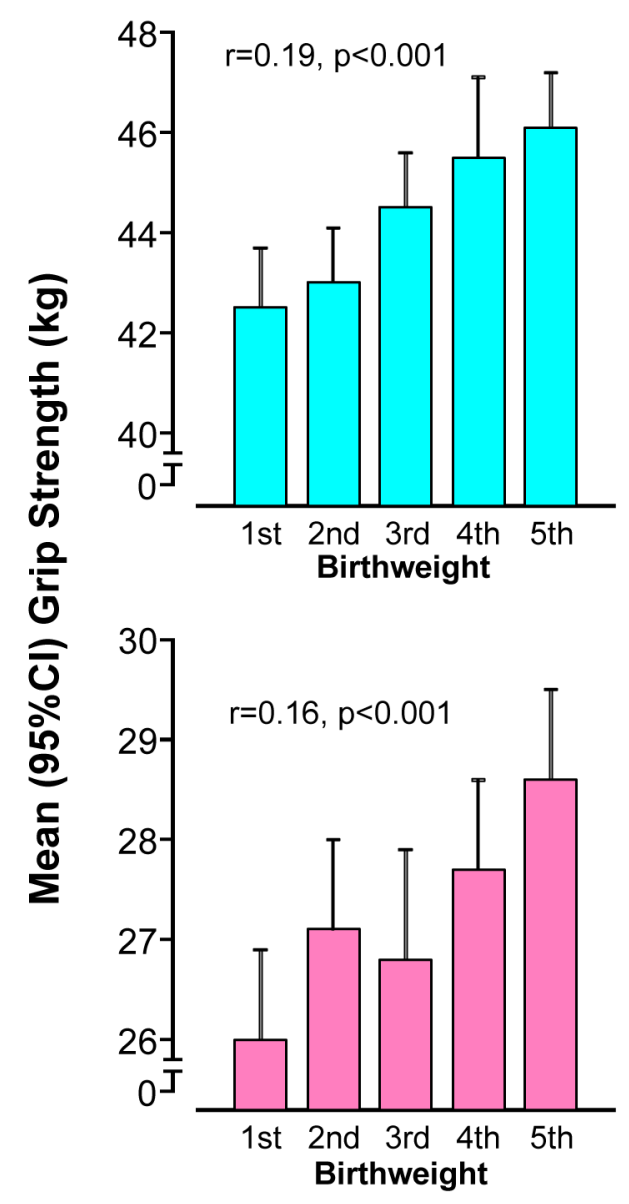

MEN
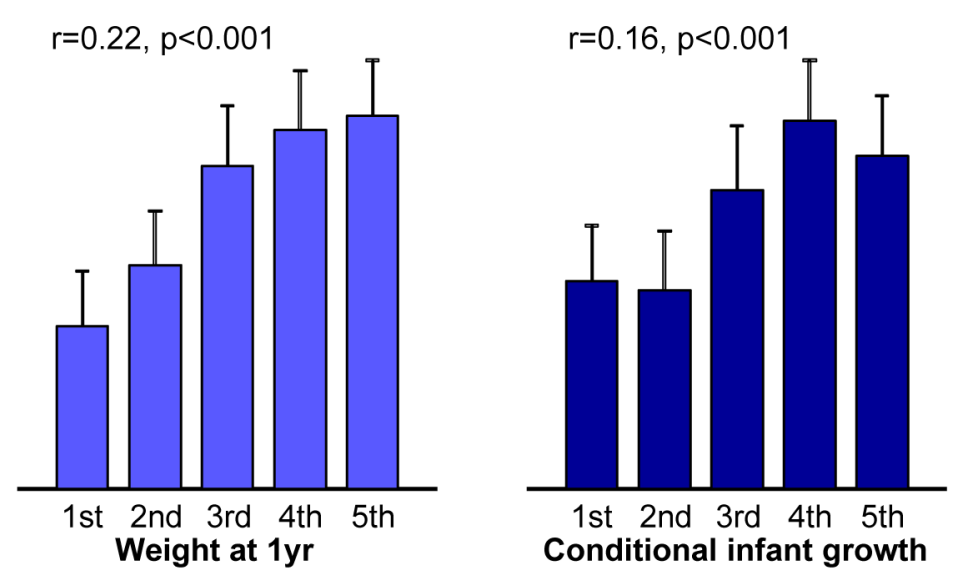

WOMEN
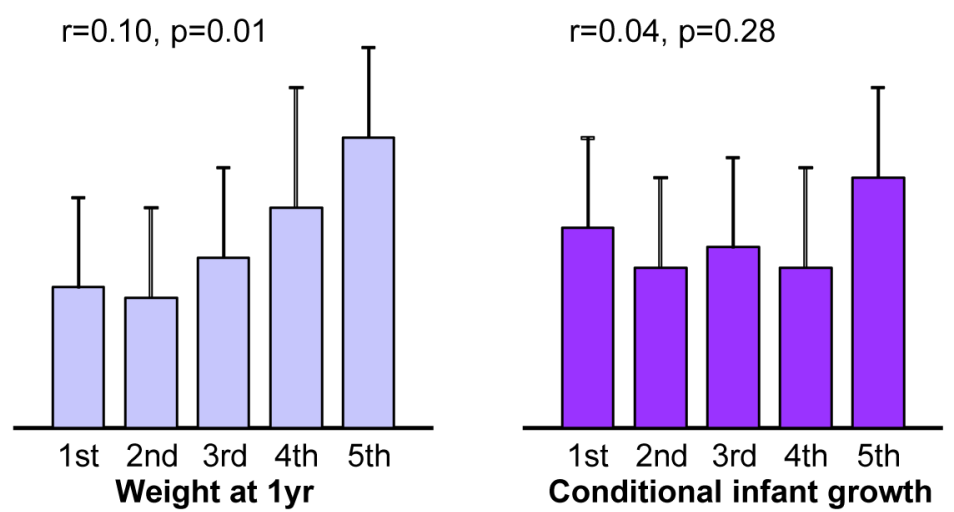

Figure 2.

Relationships between early size and growth and adult grip strength: findings from the Hertfordshire Cohort Study 18

Footnote: Grip strength presented according to quintiles of early size and growth 


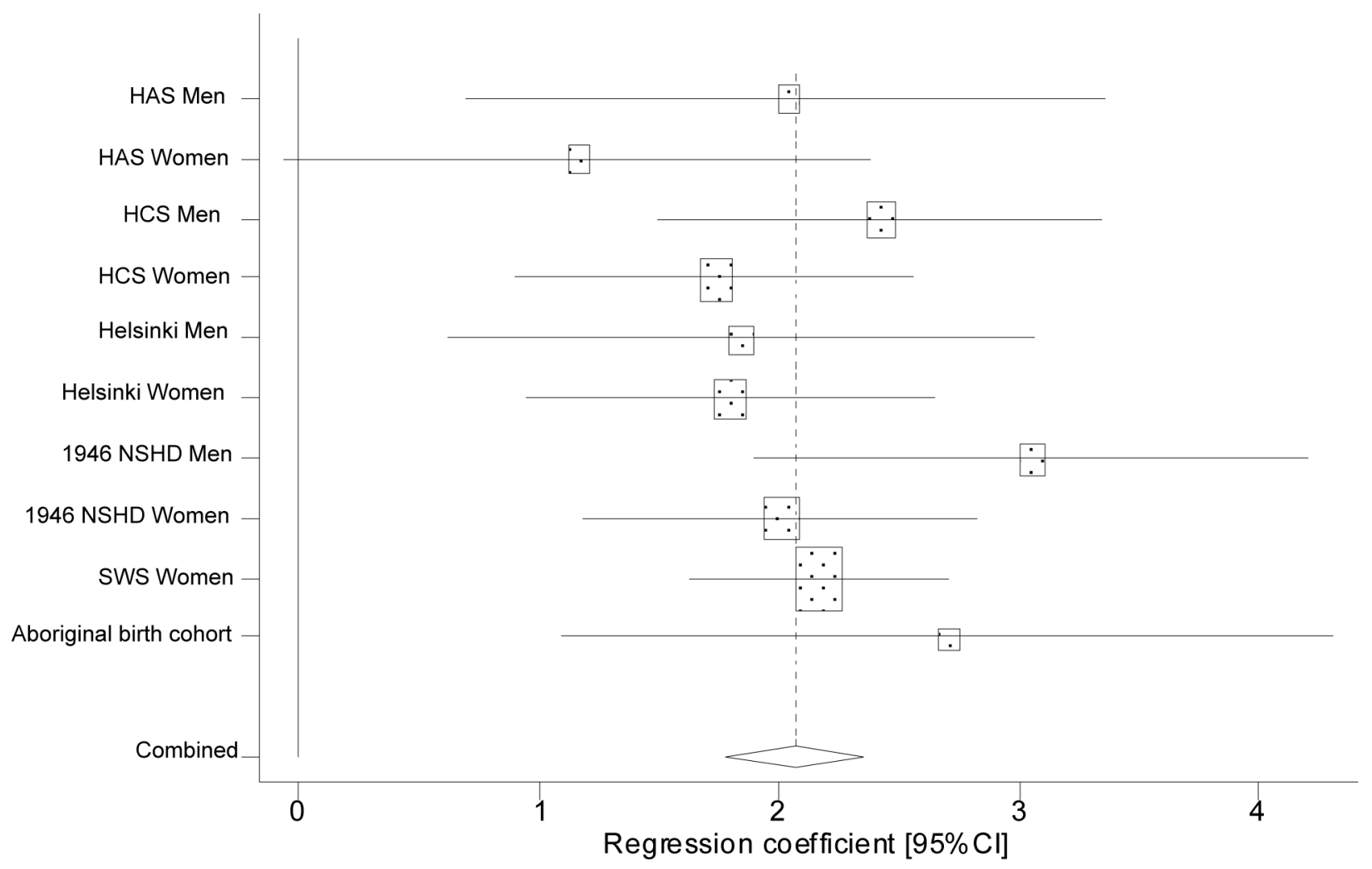

Figure 3.

Meta-analysis of the association between birth weight and grip strength in later life 


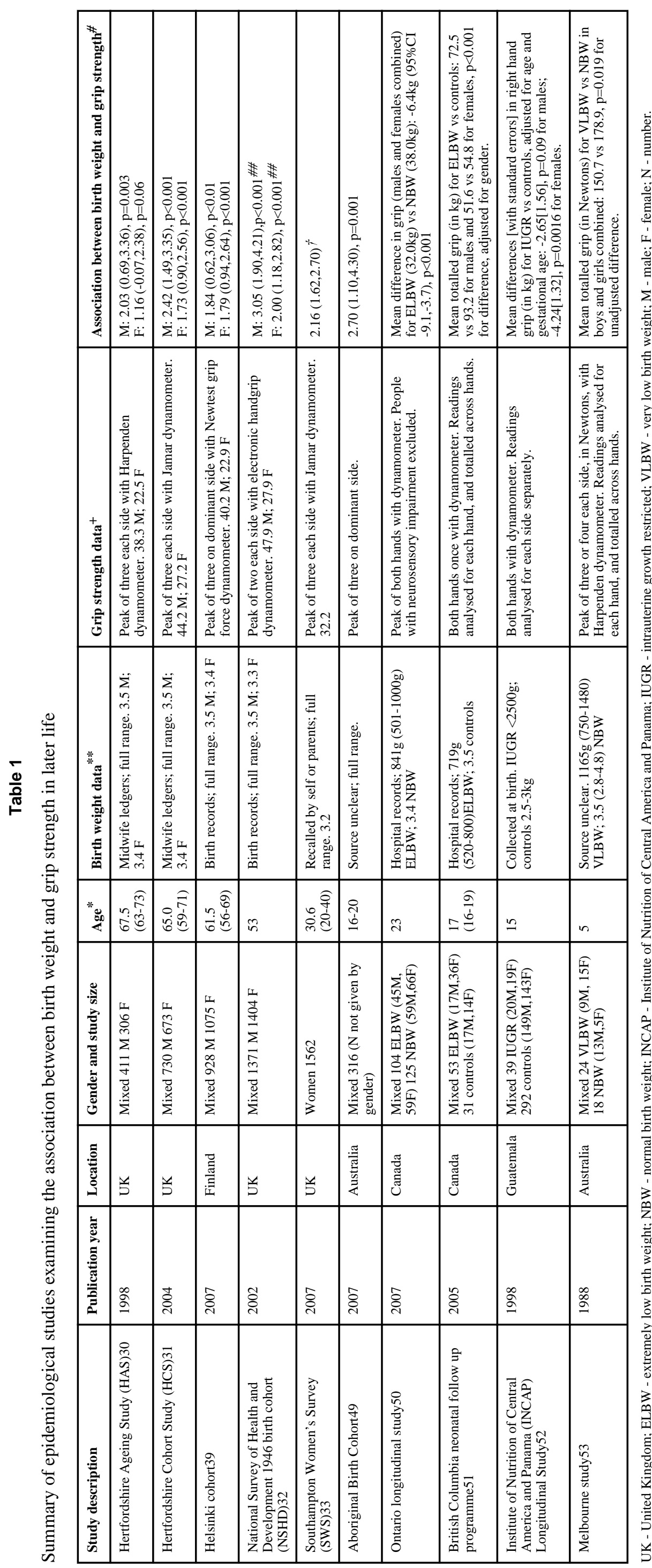

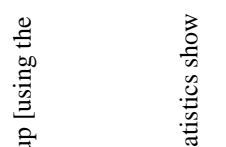

更

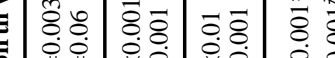

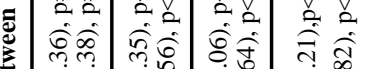

帘

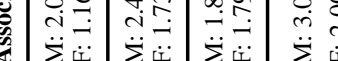

的

要

迹

竞

(⿱艹)

突然

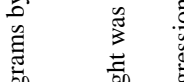

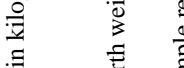


